\title{
Consensus on management of castration-resistant prostate cancer on behalf of the Urological Tumours Working Group (URONCOR) of the Spanish Society of Radiation Oncology
}

\author{
A. Gómez-Caamaño ${ }^{1}$ D $\cdot$ C. González-San Segundo ${ }^{2} \cdot$ I. Henríquez $^{3} \cdot$ X. Maldonado ${ }^{4} \cdot$ A. Zapatero $^{5} \cdot$ Expert Panel for $^{-}$ \\ the Consensus on Management of Castration-Resistant Prostate Cancer 2017, Urological Tumours Working Group \\ (URONCOR), Spanish Society of Radiation Oncology (SEOR)
}

Received: 23 March 2018 / Accepted: 2 September 2018 / Published online: 6 October 2018

(c) The Author(s) 2018

\begin{abstract}
Background The knowledge in the field of castration-resistant prostate cancer (CRPC) is developing rapidly, with emerging new therapies and advances in imaging. Nonetheless, in multiple areas there is still a lack of or very limited evidence, and clear guidance from clinicians regarding optimal strategy is required.

Methods A modified Delphi method, with 116 relevant questions divided into 7 different CRPC management topics, was used to develop a consensus statement by the URONCOR group.

Results A strong consensus or unanimity was reached on $93 \%$ of the proposed questions. The seven topics addressed were: CRPC definition, symptomatic patients, diagnosis of metastasis, CRPC progression, M0 management, M1 management and sequencing therapy, and treatment monitoring.

Conclusions The recommendations based on the radiation oncology experts' opinions are intended to provide cancer specialists with expert guidance and to standardise CRPC patient management in Spain, facilitating decision-making in different clinically relevant issues regarding CRPC patients.
\end{abstract}

Keywords Castration-resistant prostate cancer · Radiation oncology $\cdot$ Consensus · Delphi · Management $\cdot$ Metastasic . Therapeutics · Oligometastasic prostate cancer

Electronic supplementary material The online version of this article (https://doi.org/10.1007/s12094-018-1940-2) contains supplementary material, which is available to authorized users.

The members of the Expert Panel for the Consensus on Management of Castration-Resistant Prostate Cancer 2017, Urological Tumours Working Group (URONCOR), Spanish Society of Radiation Oncology (SEOR) mentioned in the Acknowledgements section.

A. Gómez-Caamaño

antonio.gomez.caamano@sergas.es

1 Radiation Oncology Department, Hospital Clínico Universitario de Santiago de Compostela, A Coruña, Spain

2 Radiation Oncology Department, Hospital General Universitario Gregorio Marañón, Madrid, Spain

\section{Introduction}

Prostate cancer is the second most common cancer in men worldwide. In recent years, in Europe as in Spain, it has been the most frequent $(360,000$ cases diagnosed in the EU-27 in 2012 and 33,370 new cases in Spain in 2015) [1], with the incidence presenting a significant increase after the fifth decade. In 2012 it was the malignancy with the highest incidence and prevalence in Spain $(12.9 \%)$ [2, 3]. Data from population-based cancer registries in Spain have shown an improvement in prostate cancer prognosis, with $84.5 \%$

3 Radiation Oncology Department, Hospital Universitario Sant Joan de Reus, Tarragona, Spain

4 Radiation Oncology Department, Hospital Campus Vall d'Hebron, Barcelona, Spain

5 Radiation Oncology Department, Hospital Universitario de La Princesa, Madrid, Spain 
5-year relative survival (95\% CI 83.6-85.6\%) [4]. However, this survival rate drops rapidly among the older age patients with an advanced stage of the disease at diagnosis [5].

Although most patients initially respond to medical radiation or surgical therapy, around $10-20 \%$ of prostate cancer patients develop a castration-resistant prostate cancer (CRPC), within 5 years of follow-up [6]. CRPC is a heterogeneous disease, with metastases present in over $84 \%$ of patients [7], deterioration in the quality of life and shorter survival compared with castration-sensitive patients $[6,8]$.

Treatment for CRPC has improved considerably in these recent years, with several agents extending life, including androgen-receptor pathway therapies (enzalutamide, abiraterone) $[9,10]$, autologous cellular immunotherapy (sipuleucel-T, not available in Europe) [11], radium-223 [12] and cabazitaxel [13]. Despite these new emerging therapies, there is an absence of face-to-face comparative studies between therapeutic options. Therefore, there is still controversy on how to sequence or combine these therapies in order to provide the greatest benefits to the patients [14].

Furthermore, with the availability of new imaging tools the diagnoses of metastasis and progression in CPRC is constantly evolving and there are no clear recommendations on when to initiate imaging or the testing frequency in clinical practice. The usefulness of new imaging technique in advanced prostate cancer and its clinical benefit will be answered in trials that directly assess these techniques.

To address this issue, the SEOR Urological Tumour Working Group (URONCOR) consulted a working panel of 25 radiation oncologist experts in order to provide a consensus on many controversial aspects in CRPC management, including the definition of CRPC, aspects relating to symptomatic patients, diagnosis of metastasis, CRPC progression, M0 management, M1 management and sequencing therapy, and the monitoring of treatment. The conclusions were used to generate a document intended to standardise CRPC patient management and to facilitate decision-making in this stage across Spain.

\section{Materials and methods}

The consultation process followed a modified Delphi method. In the first phase, a scientific committee with 4 radiation oncologists plus a coordinator (supplementary data) identified several critical controversial areas in CRPC and developed a questionnaire covering 7 topics with a total of 116 questions. In the second phase, URONCOR sent the questionnaire to a working panel of 25 experts (supplementary data) to obtain their opinions on best practice. The questions were answered in two separate rounds and a face-to-face meeting, where panelists were able to discuss their answers and to vote again on any conflicting items through an anonymous televoting system (9-10 February 2017, Madrid, Spain).

Questions that resulted in an absolute consensus (100\%) were classified as having unanimity, $80 \%$ or more was classified as a strong consensus, $70-79 \%$ represented a moderate consensus and $29-69 \%$ was defined as having no consensus. Issues that reached a moderate consensus or had no consensus in the second round were debated in the face-to-face meeting.

\section{Results}

The questionnaire covered a total of 116 clinically relevant issues categorised under 7 controversial areas relating to CRPC and its treatment: CRPC definition, (Topic 1), Symptomatic patients (Topic 2), Diagnosis of metastasis (Topic 3), CRPC progression (Topic 4), M0 management (Topic 5), M1 management and sequencing therapy (including metastasis monitoring; Topic 6) and Monitoring of response (Topic 7).

After the two rounds and the face-to-face meeting, a consensus was reached on 108 of the 116 questions (93\%), with unanimity on 22 items (19.0\%) and a strong consensus on 86 questions (74.1\%). Three questions (2.6\%) reached a moderate consensus while the remaining five questions had no consensus (4.3\%) (Figs. 1 and 2, Table 1).

Table 2 shows the voting results of the expert panel obtained by the Urological Tumours Working Group (URONCOR) of the Spanish Society of Radiation Oncology (SEOR).

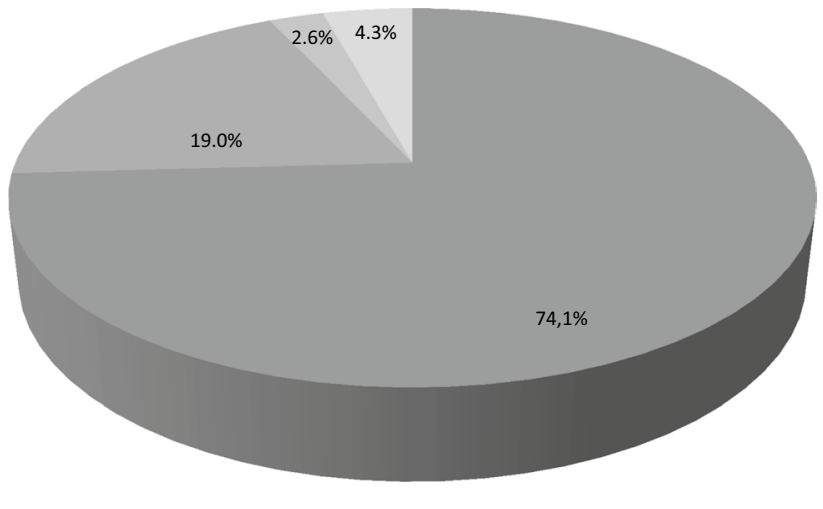

Strong consensus Unanimity Moderate consensus No consensus

Fig. 1 Consensus after the face-to-face session (percentage) 


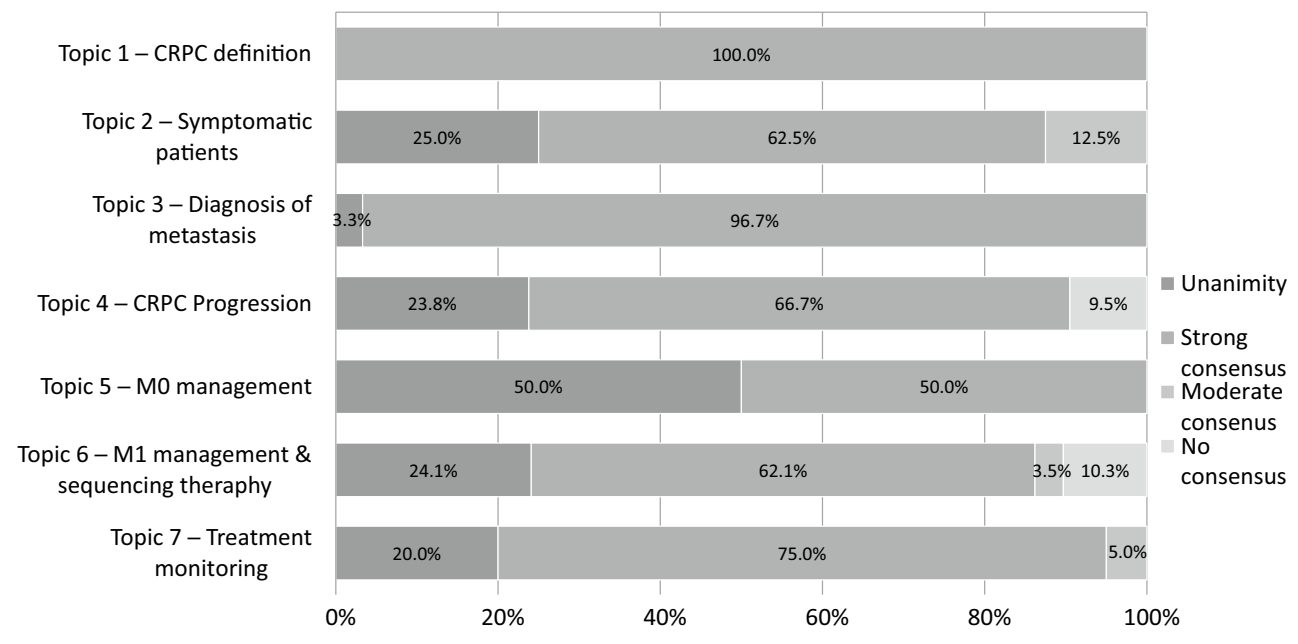

Fig. 2 Results by topic (percentage) of the consensus after the face-to-face session

Table 1 Results of the consensus reached after the face-to-face session by topic (number of questions, percentage)

\begin{tabular}{|c|c|c|c|c|c|}
\hline & $N$ & $\begin{array}{l}\text { Unanimity } \\
N(\%)\end{array}$ & $\begin{array}{l}\text { Strong consensus } \\
N(\%)\end{array}$ & $\begin{array}{l}\text { Consensus } \\
N(\%)\end{array}$ & $\begin{array}{l}\text { No Consensus } \\
N(\%)\end{array}$ \\
\hline Topic 1 -CRPC definition & 2 & & $100.0 \%$ & & \\
\hline Topic 2-Symptomatic patients & 8 & $25.0 \%$ & $62.5 \%$ & $12.5 \%$ & \\
\hline Topic 3-Diagnosis of metastasis & 30 & $3.3 \%$ & $96.7 \%$ & & \\
\hline Topic 4-CRPC progression & 21 & $23.8 \%$ & $66.7 \%$ & & $9.5 \%$ \\
\hline Topic 5-M0 management & 6 & $50.0 \%$ & $50.0 \%$ & & \\
\hline $\begin{array}{l}\text { Topic } 6 \text {-M1 management and } \\
\text { sequencing therapy }\end{array}$ & 29 & $24.1 \%$ & $62.1 \%$ & $3.5 \%$ & $10.3 \%$ \\
\hline \multirow[t]{2}{*}{ Topic 7-Treatment monitoring } & 20 & $20.0 \%$ & $75.0 \%$ & $5.0 \%$ & \\
\hline & 116 & $22(19 \%)$ & $86(74.1 \%)$ & $3(2.6 \%)$ & $5(4.3 \%)$ \\
\hline
\end{tabular}

\section{Consensus development and panel discussion}

\section{Topic 1-CRPC definition}

Several definitions of CRPC have been proposed over time. Similarly, the diagnostic criteria used in clinical studies have been extremely heterogeneous [6]. Recently, the European Expert Consensus Panel [15] defined CRPC patients as men with castrate serum testosterone levels and confirmed PSA progression. Spanish urologist experts added radiological progression to the definition of CRPC [16]. The St Gallen expert group considered that a confirmed rising PSA is sufficient to diagnose CRPC in patients on ADT with castrate levels of testosterone [17].

The panel strongly agreed (96\%) that CRPC was defined by a documented rising PSA ( $\geq 2 \mathrm{ng} / \mathrm{ml})$ and/or radiological progression in men with testosterone levels of $<50 \mathrm{ng} / \mathrm{dl}$ $(<1.7 \mathrm{nmol} / \mathrm{l})$. In addition, they strongly agreed $(88 \%)$ that a rising PSA after the use of 2 or more hormonal therapies was not required to define CRPC.

\section{Topic 2-Symptomatic patients}

In the TAX327 trial, pain response was found to be a prognostic end-point for overall survival, even if it did not meet strict surrogacy criteria [18]. There is a degree of uncertainty among the end-point criteria on whether to consider an asymptomatic/minimally symptomatic patient in clinical trials $[11,19]$. The URONCOR consensus statement agreed to define these patients as those with bone metastasis without pain or mild/moderate pain controlled with first- or second-line WHO pain scale analgesics [20], or patients who have shown a good analgesic response to palliative RT and/ or to bisphosphonates [21]. In addition, different publications support the use of symptom assessment tools to evaluate pain in CRPC [22-24].

The panel agreed that a minimally symptomatic CRPC patient was defined as having a low score in validated pain scales (100\%) and showing a response to non-steroidal antiinflammatory drugs (NSAID) (100\%). A strong consensus was reached on previous response to antialgic radiotherapy $(80 \%)$ whereas opioid response was considered irrelevant 
Table 2 Consensus panel voting results on CRPC from the Urological Tumour Working Group (URONCOR) of the Spanish Society of Radiation Oncology

\begin{tabular}{|c|c|c|c|}
\hline & Yes & No & Consensus level \\
\hline \multicolumn{4}{|l|}{ Topic 1 - CRPC definition } \\
\hline \multicolumn{4}{|l|}{ In patients with castrate levels of testosterone, CRPC can be defined as: } \\
\hline Confirmed PSA progression $(>2 \mathrm{ng} / \mathrm{ml})$ and/or radiological progression & $96 \%$ & $4 \%$ & $\mathrm{SC}$ \\
\hline $\begin{array}{l}\text { Confirmed PSA progression }(>2 \mathrm{ng} / \mathrm{ml}) \text { and/or radiological progression after } \geq 2 \text { prior } \\
\text { hormonal therapies }\end{array}$ & $12 \%$ & $\mathbf{8 8 \%}$ & $\mathrm{SC}$ \\
\hline \multicolumn{4}{|l|}{ Topic 2-Symptomatic patients } \\
\hline \multicolumn{4}{|l|}{ Criteria to define a minimally symptomatic patient } \\
\hline Low score on validated pain scales & $100 \%$ & $0 \%$ & $\mathrm{U}$ \\
\hline Pain response to NSAID/paracetamol & $100 \%$ & $0 \%$ & $\mathrm{U}$ \\
\hline Pain control by opioids & $12 \%$ & $\mathbf{8 8} \%$ & $\mathrm{SC}$ \\
\hline Previous response to antalgic radiotherapy & $80 \%$ & $20 \%$ & $\mathrm{SC}$ \\
\hline \multicolumn{4}{|l|}{ Scales used to assess the patient's pain: } \\
\hline BPI-SF (Brief Pain Inventory - Short Form) & $\mathbf{9 2 \%}$ & $8 \%$ & $\mathrm{SC}$ \\
\hline Visual analogic scale & $96 \%$ & $4 \%$ & $\mathrm{SC}$ \\
\hline Subjective patient assessment/verbal scales & $28 \%$ & $72 \%$ & $\mathrm{MC}$ \\
\hline Scales are not important in evaluating patient pain & $4 \%$ & $96 \%$ & $\mathrm{SC}$ \\
\hline \multicolumn{4}{|l|}{ Topic 3-Diagnosis of metastasis } \\
\hline \multicolumn{4}{|l|}{ Bone scan (BS) } \\
\hline \multicolumn{4}{|l|}{ In a CPRC patient, a BS would be appropriate to perform in the following scenarios: } \\
\hline At CRPC diagnosis, regardless of PSA levels & $\mathbf{8 8 \%}$ & $12 \%$ & $\mathrm{SC}$ \\
\hline When PSA level is $>10 \mathrm{ng} / \mathrm{ml}$ and/or PSA-DT at $<6$ months & $\mathbf{9 2 \%}$ & $8 \%$ & $\mathrm{SC}$ \\
\hline At the onset of bone pain & $\mathbf{9 2 \%}$ & $8 \%$ & $\mathrm{SC}$ \\
\hline \multicolumn{4}{|c|}{ Given a negative BS in an asymptomatic M0 CRPC patient, the test would be repeated under the following circumstances: } \\
\hline PSA level of $>10 \mathrm{ng} / \mathrm{ml}$ and/or PSA-DT at $<6$ months & $\mathbf{9 2 \%}$ & $8 \%$ & $\mathrm{SC}$ \\
\hline PSA level of $>2 \mathrm{ng} / \mathrm{ml}$ and/or PSA-DT at 6-12 months & $16 \%$ & $84 \%$ & $\mathrm{SC}$ \\
\hline Every 3-6 months regardless of PSA values & $20 \%$ & $\mathbf{8 0 \%}$ & $\mathrm{SC}$ \\
\hline Exclusively with the onset of pain & $16 \%$ & $84 \%$ & $\mathrm{SC}$ \\
\hline \multicolumn{4}{|l|}{ In a CPRC patient with bone pain, in the event of a negative/inconsistent BS: } \\
\hline Wait to know what the PSA kinetics are & $12 \%$ & $\mathbf{8 8 \%}$ & $\mathrm{SC}$ \\
\hline $\begin{array}{l}\text { An additional imaging test is required (standard x-rays of areas of concern, axial skeleton } \\
\text { MRI scan, CT bone scan or choline PET/CT) }\end{array}$ & $\mathbf{9 2 \%}$ & $8 \%$ & $\mathrm{SC}$ \\
\hline \multicolumn{4}{|l|}{ CT Scan } \\
\hline \multicolumn{4}{|l|}{ In a CPRC patient, a chest, abdomen and pelvis $\mathrm{CT}$ scan would be appropriate to perform: } \\
\hline At CRPC diagnosis, regardless of PSA levels & $96 \%$ & $4 \%$ & $\mathrm{SC}$ \\
\hline With a PSA level of $>10 \mathrm{ng} / \mathrm{ml}$ and/or PSA-DT at $<6$ months & $\mathbf{8 8 \%}$ & $12 \%$ & $\mathrm{SC}$ \\
\hline At the onset of metastatic related symptoms & $96 \%$ & $4 \%$ & $\mathrm{SC}$ \\
\hline \multicolumn{4}{|l|}{ In a CPRC M0 asymptomatic patient, with a negative CT scan, the following test should be repeated: } \\
\hline With a PSA level of $>10 \mathrm{ng} / \mathrm{ml}$ and/or PSA-DT at $<6$ months & $96 \%$ & $4 \%$ & $\mathrm{SC}$ \\
\hline With a PSA level of $>2 \mathrm{ng} / \mathrm{ml}$ and/or PSA-DT at 6-12 months & $16 \%$ & $84 \%$ & $\mathrm{SC}$ \\
\hline Every 3-6 months regardless of PSA values & $16 \%$ & $84 \%$ & $\mathrm{SC}$ \\
\hline Only if they present symptoms & $16 \%$ & $84 \%$ & $\mathrm{SC}$ \\
\hline \multicolumn{4}{|l|}{ In a symptomatic CPRC patient, in the event of a negative/inconsistent CT Scan: } \\
\hline Wait to know what the PSA kinetics are & $12 \%$ & $\mathbf{8 8 \%}$ & $\mathrm{SC}$ \\
\hline An additional imaging test is required (whole-body MRI or choline PET/CT) & $100 \%$ & $0 \%$ & $\mathrm{U}$ \\
\hline \multicolumn{4}{|l|}{ Choline PET/CT/Whole-body MRI } \\
\hline \multicolumn{4}{|l|}{ Performing PET/CT would be appropriate for CRPC patients: } \\
\hline In order to confirm inconclusive M1 test results & $\mathbf{8 8 \%}$ & $12 \%$ & $\mathrm{SC}$ \\
\hline Following a negative conventional cancer staging study (CT and BS) & $12 \%$ & $\mathbf{8 8 \%}$ & $\mathrm{SC}$ \\
\hline
\end{tabular}


Table 2 (continued)

\begin{tabular}{|c|c|c|c|}
\hline & Yes & No & Consensus level \\
\hline $\begin{array}{l}\text { Following a negative conventional cancer staging study (CT and BS) and aggressive PSA } \\
\text { kinetics }\end{array}$ & $96 \%$ & $4 \%$ & $\mathrm{SC}$ \\
\hline \multicolumn{4}{|l|}{ Performing a whole-body MRI would be the best option for CRPC patients: } \\
\hline In order to confirm inconclusive M1 test results & $100 \%$ & $0 \%$ & $\mathrm{U}$ \\
\hline Following a negative conventional cancer staging study (CT and BS) & $20 \%$ & $\mathbf{8 0 \%}$ & SC \\
\hline $\begin{array}{l}\text { Following a negative conventional cancer staging study (CT and BS) and aggressive PSA } \\
\text { kinetics }\end{array}$ & $80 \%$ & $20 \%$ & SC \\
\hline \multicolumn{4}{|l|}{ Oligometastatic CPRC patient } \\
\hline \multicolumn{4}{|l|}{ Definition criteria: } \\
\hline Lack of visceral disease & $8 \%$ & $\mathbf{9 2 \%}$ & $\mathrm{SC}$ \\
\hline Ganglionic and/or bone disease ( 5 areas or fewer) & $92 \%$ & $8 \%$ & $\mathrm{SC}$ \\
\hline \multicolumn{4}{|l|}{ Images needed in order to diagnose the oligometastatic CPRC patient: } \\
\hline $\mathrm{CT}$ and $\mathrm{BS}$ & $84 \%$ & $16 \%$ & SC \\
\hline Choline PET/CT & $\mathbf{8 8} \%$ & $12 \%$ & $\mathrm{SC}$ \\
\hline Whole-body MRI & $80 \%$ & $20 \%$ & $\mathrm{SC}$ \\
\hline \multicolumn{4}{|l|}{ Do you agree with the following statement? } \\
\hline $\begin{array}{l}\text { Choline PET/TC is not useful to identify oligometastasis in patients with a low PSA level } \\
(\leq 1 \mathrm{ng} / \mathrm{ml})\end{array}$ & $96 \%$ & $4 \%$ & $\mathrm{SC}$ \\
\hline \multicolumn{4}{|l|}{ Topic 4 -CRPC progression } \\
\hline \multicolumn{4}{|l|}{ Do you agree that the following statements define the progression of a CPRC patient? } \\
\hline Exclusive biochemical progression & $12 \%$ & $\mathbf{8 8 \%}$ & SC \\
\hline Radiological progression & $96 \%$ & $4 \%$ & $\mathrm{SC}$ \\
\hline Clinical progression (pain, overall status) & $\mathbf{8 8 \%}$ & $12 \%$ & SC \\
\hline \multicolumn{4}{|c|}{ Which statements define primary resistance to therapies targeting the androgen receptor pathway (enzalutamide/abiraterone): } \\
\hline Absence of decline in PSA level $(\geq 30 \%)$ during the first 3 months & $12 \%$ & $\mathbf{8 8} \%$ & SC \\
\hline Sustained PSA progression within 3-4 months of therapy initiation & $68 \%$ & $32 \%$ & $\mathrm{NC}$ \\
\hline Radiological progression within 3-4 months of therapy initiation & $\mathbf{9 2 \%}$ & $8 \%$ & SC \\
\hline \multicolumn{4}{|l|}{ Statements related to the flare-up occurrence } \\
\hline $\begin{array}{l}\text { A flare-up is defined as a temporary clinical and/or biochemical worsening since therapy } \\
\text { initiation }\end{array}$ & $\mathbf{9 2 \%}$ & $8 \%$ & $\mathrm{SC}$ \\
\hline A flare-up occurs with taxane treatment & $100 \%$ & $0 \%$ & $\mathrm{U}$ \\
\hline A flare-up occurs with enzalutamide treatment & $56 \%$ & $44 \%$ & $\mathrm{NC}$ \\
\hline A flare-up occurs with abiraterone treatment & $100 \%$ & $0 \%$ & $\mathrm{U}$ \\
\hline \multicolumn{4}{|l|}{ The following parameters are predictive factors of poor response to therapies: } \\
\hline High primary tumour Gleason score & $100 \%$ & $0 \%$ & $\mathrm{U}$ \\
\hline Short response duration after first-line hormonal therapy (LHRH) & $96 \%$ & $4 \%$ & $\mathrm{SC}$ \\
\hline Presence of visceral metastasis & $100 \%$ & $0 \%$ & $\mathrm{U}$ \\
\hline Short PSA-DT & $96 \%$ & $4 \%$ & $\mathrm{SC}$ \\
\hline High LDH and/or alkaline phosphatase & $\mathbf{9 2 \%}$ & $8 \%$ & $\mathrm{SC}$ \\
\hline Moderate to severe pain score & $92 \%$ & $8 \%$ & SC \\
\hline Overall poor condition (ECOG performance status) & $100 \%$ & $0 \%$ & $\mathrm{U}$ \\
\hline \multicolumn{4}{|l|}{ The following parameters are prognostic factors of disease progression: } \\
\hline Presence of circulating tumour cells $(\geq 5 / 7.5 \mathrm{ml})$ & $\mathbf{8 4 \%}$ & $16 \%$ & $\mathrm{SC}$ \\
\hline Presence of androgen receptor splice variant (AR-V7) & $\mathbf{9 2 \%}$ & $8 \%$ & $\mathrm{SC}$ \\
\hline \multicolumn{4}{|l|}{ Do you agree with the following definition of the biochemical progression of the CPRC patient? } \\
\hline $\begin{array}{l}\text { Three consecutive PSA increases one week apart, resulting in two } 50 \% \text { increases over the } \\
\text { nadir and a PSA level of }>2 \mathrm{ng} / \mathrm{ml}\end{array}$ & $88 \%$ & $12 \%$ & $\mathrm{SC}$ \\
\hline $\begin{array}{l}\text { Three consecutive PSA increases one week apart, resulting in two } 50 \% \text { increases over the } \\
\text { nadir and a PSA level of }>1 \mathrm{ng} / \mathrm{ml}\end{array}$ & $12 \%$ & $\mathbf{8 8 \%}$ & $\mathrm{SC}$ \\
\hline
\end{tabular}


Table 2 (continued)

Yes No Consensus level

Topic 5-M0 management

In an M0 CRPC patient, do you agree with the following statements?

An initial BS should be requested for PSA levels of $>2 \mathrm{ng} / \mathrm{ml}$

$\mathbf{8 4} \% \quad 16 \% \quad \mathrm{SC}$

For PSA levels of $>2 \mathrm{ng} / \mathrm{ml}$ and negative BS, the test should be repeated when PSA levels $\mathbf{8}$ reach $\geq 5 \mathrm{ng} / \mathrm{ml}$

For PSA levels of $\geq 5 \mathrm{ng} / \mathrm{ml}$ and negative BS, the test should be repeated each time the PSA level doubles and PSA should be tested every 3 months

$\mathbf{8 8} \% \quad 12 \% \quad$ SC

In an M0 CRPC patient with local clinical progression, the first-line therapy would be:

Radiotherapy (if no prior RT) or salvage surgery

Docetaxel

$\begin{array}{lll}\mathbf{1 0 0} \% & 0 \% & \mathrm{U} \\ 0 \% & \mathbf{1 0 0 \%} & \mathrm{U} \\ 0 \% & \mathbf{1 0 0 \%} & \mathrm{U}\end{array}$

New antiandrogen therapies (enzalutamide/abiraterone)

Topic 6-M1 management and sequencing therapy

In an asymptomatic/minimally symptomatic M1 CRPC patient the first-line therapy would be:

\begin{tabular}{|c|c|c|}
\hline Enzalutamide/abiraterone in most cases & $100 \%$ & $0 \%$ \\
\hline Docetaxel in most cases & $0 \%$ & $100 \%$ \\
\hline Docetaxel in some aggressive cases & $92 \%$ & $8 \%$ \\
\hline
\end{tabular}

In an initially asymptomatic or minimally symptomatic M1 CRPC patient, the following factors would influence the choice of treatment:

\begin{tabular}{llll} 
Visceral metastases & $\mathbf{9 6 \%}$ & $4 \%$ & \multicolumn{2}{c}{} & SC \\
Hypertension & $44 \%$ & $56 \%$ & NC \\
History of cardiovascular disease & $\mathbf{7 2 \%}$ & $28 \%$ & $\mathbf{M C}$ \\
History of seizures & $\mathbf{8 0} \%$ & $20 \%$ & $\mathbf{S C}$ \\
Contradindications for steroid use & $\mathbf{9 6 \%}$ & $4 \%$ & $\mathbf{S C}$
\end{tabular}

In an asymptomatic/minimally symptomatic M1 CRPC patient with visceral metastasis, first-line therapy would be:

\begin{tabular}{|c|c|c|}
\hline Enzalutamide & $80 \%$ & $20 \%$ \\
\hline Abiraterone & $0 \%$ & $100 \%$ \\
\hline Docetaxel & $20 \%$ & $80 \%$ \\
\hline
\end{tabular}

In an asymptomatic/minimally symptomatic M1 CRPC patient, secondary hormonal manipulations

Are suitable for patients who are not candidates for chemotherapy only when enzaluta- $\quad \mathbf{8 8 \%}$ mide/abiraterone are not available

Are suitable for patients who are not candidates for chemotherapy regardless of enzaluta- $\quad 0 \%$ mide/abiraterone availability

Are suitable for all patients, regardless of whether they are chemotherapy candidates or $\quad 4 \%$ not

If there is progression...

A biopsy of the metastatic lesion would be performed to check for a change in the tumour $52 \%$ phenotype.

In a symptomatic M1 CRPC patient the first-line therapy would be:

New antiandrogenic drugs (enzalutamide/abiraterone)

$16 \% \quad \mathbf{8 4 \%} \quad \mathrm{SC}$

Docetaxel

Radium-223 (in bone/non-visceral metastases)

Do you agree with the following statement?

Most CPRC with symptomatic bone metastases should be treated with bone-targeting therapies (bisphosphonate, denosumab, if there areno contraindications).

$\mathbf{8 8} \% \quad 12 \% \quad$ SC

If you answered yes to the previous question, the bone-targeting therapies must be continued:

For 12-24 months

Until the onset of bone progression

The local control of oligometastasis...

Decreases symptoms.

$\mathbf{9 2} \% \quad 8 \%$

Delays the start of a new systemic treatment

Increases overall/progression-free survival

$\mathbf{8 8} \% \quad 12 \%$

$\mathbf{8 4} \% \quad 16 \%$


Table 2 (continued)

Yes

No

Consensus level

In oligometastatic CPRC patients...

Local ablative therapy in addition to the new antiandrogenic drugs (enzalutamide/abiraterone) must be considered

A radical prostate treatment should be performed

$\mathbf{9 2} \% \quad 8 \% \quad$ SC

In the CPRC patient the following supportive therapies must be offered:

Calcium and vitamin D when denosumab or bisphosphonates are prescribed

$100 \%$

$0 \%$

$\mathrm{U}$

External radiotherapy, radiopharmaceuticals and analgesia in cases of painful bone metastases

Corticosteroids and surgical evaluation and radiation in patients with spinal cord compression

Topic 7-Treatment monitoring

Imaging test suitable to evaluate bone metastasis response to the therapy

Tc-99 $\mathrm{m}$ bone scan

$\mathbf{8 4} \% \quad 16 \%$

$\mathbf{9 2} \% \quad 8 \%$

$\mathbf{8 4} \% \quad 16 \%$

$\mathrm{SC}$

Whole body MRI and/or axial skeleton

$\mathrm{SC}$

Choline PET/TC

In an asymptomatic/minimally symptomatic CPRC patient, does the first-line therapy choice influence the frequency of patient monitoring in the following?

Follow-up patient visits

Imaging tests frequency

Analytic testing

$\mathbf{1 0 0 \%} \quad 0 \% \quad \mathrm{U}$

$4 \% \quad 96 \% \quad$ SC

$\mathbf{8 4 \%} \quad 16 \% \quad$ SC

$\begin{array}{llll}\text { Additional blood pressure monitoring } & \mathbf{8 0} \% & 20 \% & \text { SC }\end{array}$

If you answered yes, which is your preferred choice of action during the first 3 months of enzalutamide therapy:

\begin{tabular}{|c|c|c|c|}
\hline & $1 / 2$ weeks & Monthly & Quarterly \\
\hline Frequent follow-up visits & $4 \%$ & $\mathbf{8 0} \%$ & $16 \%$ \\
\hline Imaging tests frequency & $14 \%$ & $84 \%$ & $12 \%$ \\
\hline Analytic testing & $10 \%$ & $70 \%$ & $20 \%$ \\
\hline
\end{tabular}

If you answered yes, which is your preferred choice of action during the first 3 months of abiraterone therapy:

Frequent follow-up visits

$1 / 2$ weeks Monthly Quarterly

Analytic testing

$\mathbf{9 2} \% \quad 8 \% \quad 0 \% \quad \mathrm{SC}$

Additional blood pressure monitoring

84\%

$85 \%$

$16 \% \quad 0 \%$

$0 \% \quad \mathrm{SC}$

In an asymptomatic/minimally symptomatic M1 CPRC patient, follow-up tests must be performed:

Every 3-6 months, regardless of PSA values

$\mathbf{8 8 \%}$

$96 \%$

$12 \%$

$100 \%$

$4 \%$

$0 \%$

$\mathbf{8 4} \% \quad 16 \%$

$4 \% \quad 96 \%$

96\% $4 \%$

$100 \% \quad 0 \%$

In the event of new symptoms appearing

Values in bold indicate the consensus

$U$ unanimity, $S C$ strong consensus, $M C$ moderate consensus, $N C$ no consensus, $C R P C$ castration-resistant prostate cancer, $P S A$ prostate-specific antigen, NSAID non-steroidal anti-inflammatory drugs, BPI-SF short form of the Brief Pain Inventory questionnaire, $P S A-D T$ prostate-specific antigen doubling-time, $M R I$ magnetic resonance imaging, $B S$ bone Scan, PET/CT positron emission tomography/computed tomography, $L H R H$ luteinizing hormone-releasing hormone, $L D H$ lactate dehydrogenase, $A R$ androgen receptor, $R T$ radiotherapy

in the definition of CRPC (88\%). The panel also strongly agreed that the BPI-SF (Brief Pain Inventory-Short Form) $(92 \%)$ and a visual analogic scale $(96 \%)$ should be used to assess patient pain.

\section{Topic 3-Diagnosis of metastasis}

There is no agreed definition on what constitutes the standard of care for detection of metastatic disease in CRPC. The EAU-ESTRO-SIOG guidelines [25] stated that in men with 
no detectable clinical metastases, baseline PSA level and PSA velocity/PSA doubling-time (DT) have been associated with the time to first bone metastasis, bone metastasis-free survival and overall survival [26, 27].

The RADAR group consensus [28] suggested that in asymptomatic men, a bone scan should be undertaken if PSA levels reached $2 \mathrm{ng} / \mathrm{ml}$ and, if negative, to undertake another bone scan if PSA reaches $5 \mathrm{ng} / \mathrm{ml}$ and every doubling of PSA level thereafter, based on PSA testing every 3 months.

The Prostate Cancer Working Group PCWG3 [22] recommends that imaging should include cross-sectional imaging (chest, abdomen, pelvis), plus bone scintigraphy.

The emerging role of the next-generation imaging methods seems promising, despite a lack of systematically conducted prospective studies. The prostate-specific membrane antigen (PSMA) PET can be considered as a highly promising tool in prostate cancer imaging due to higher detection rates, as compared with ${ }^{11} \mathrm{C}$-choline PET for lymph nodes as well as bone lesions, especially at low PSA levels [29]. Significantly, imaging strategies restricted to known sites of disease risk could miss disease progression at new sites. The NCCN (National Comprehensive Cancer Network) [30] includes MRI and PET.

The panel strongly agreed that a bone scan (BS) should be requested at CRPC diagnosis, regardless of PSA level (agreement of $88 \%$ ), with a PSA level of $>10 \mathrm{ng} / \mathrm{ml}$ and/or PSA-DT at $<6$ months (agreement of 92\%) and at the onset of bone pain $(92 \%)$.

Similarly, it was strongly agreed that a CT scan should be performed at diagnosis, regardless of PSA levels (96\%), with a PSA level of $>10 \mathrm{ng} / \mathrm{ml}$ and/or PSA-DT $<6$ months (88\%) and at the onset of metastatic related symptoms (96\%).

With regard to the use of choline PET/CT and wholebody MRI, there was a strong consensus that both tests were appropriate as a follow-up to inconclusive M1 test results (Choline PET/CT, 88\%; whole-body MRI, unanimity). The panel also strongly agreed that choline PET/CT (96\%) should be also performed in the event of a negative conventional extension study (CT and BS) and aggressive PSA kinetics. Likewise, there was a strong consensus on wholebody MRI ( $80 \%)$ being performed in this situation.

The definition of oligometastasis has evolved over time. Originally defined as five or less metastatic sites [31], it has been proposed as a clinically significant state separate from the polymetastatic disease [32], with a better prognosis and survival rates compared with patients with extensive metastatic disease [31, 32]. Significantly, aggressive local therapy [33] during this time could delay the need for systemic therapies and/or prolong progression-free survival. Recent data show that in men with PSA-recurrent prostate cancer, a prolonged metastasis-free survival is significantly associated with a longer overall survival [34]. The St Gallen consensus
2017 debated whether to propose a new clinical entity, the oligo-progressive mCRPC, but no agreement was reached on this issue [35].

The panel reached a strong consensus that the oligometastatic CRPC patient is defined as having lymph node and/ or bone disease ( 5 or fewer sites) $(92 \%)$. There was also a strong consensus that CT and BS (84\%), choline PET/CT (88\%) and whole-body MRI (80\%) should be used as diagnostic tools for these patients. Finally, there was a strong consensus (96\%) that choline PET/TC is not useful to identify oligometastasis in patients with a low PSA level $(\leq 1 \mathrm{ng} /$ $\mathrm{ml})$.

\section{Topic 4-CRPC progression}

The definition of CRPC progression is another cause for controversy and has varied over time. In many studies it has been considered as a rise in PSA levels following castration [3]. However, PSA alone is not reliable enough for monitoring disease activity in advanced CRPC because visceral metastases may develop in men without rising PSA [36]. Instead, the PCWG2 recommends a combination of bone scintigraphy and CT scans, PSA measurements, and clinical benefit in assessing men with CRPC. The PGW3 panel [22] and St. Gallen 2015 [17] stressed that agents with a proven overall survival benefit should not be stopped due to PSA progression alone. Moreover, at least two of three criteria (PSA progression, radiographic progression and clinical deterioration) should be fulfilled before stopping treatment.

In addition, the European expert panel consensus [15] defines primary resistance to AR pathway-targeted agents as a radiological progression within 3 months following therapy initiation, while a limited decrease in PSA level or progression within 3 months of therapy initiation was not sufficient for the diagnosis.

While short response to initial hormonal therapy seems to be associated with poor response to subsequent hormonal therapies, this is not always an indicator of absolute androgen independence and does not exclude any potential benefit from novel AR-targeting strategies [15], such as abiraterone or enzalutamide, which have demonstrated a positive outcome in overall survival and improvement in quality of life $[7,9]$.

There was a strong consensus that radiological (96\%) and clinical progression (pain, overall status) $(88 \%)$ had to be present in order to define disease progression. In contrast, the panel voted against an exclusive biochemical progression criteria in the definition (88\%).

In addition, the experts strongly agreed that primary resistance to enzalutamide/abiraterone is defined as radiological progression within 3-4 months of therapy initiation (92\%), while an abscense of decline in PSA level ( $\geq 30 \%)$ 
within 3 months does not serve to identify primary resistance (88\%). There was no consensus on whether sustained PSA progression within 3-4 months of therapy initiation must be present in order to define resistance to these therapies.

Even though there is no complete agreement on a precise definition of a flare occurrence, there is a broad consensus that it is characterised by a rise in the PSA level, followed by a decline below baseline values after initiating different therapies [37, 38]. A bone scan flare has been also described by the NCCN [39] and must be clearly differentiated from "disease progression". The PCWG3 suggests the use of the $2+2$ rule to distinguish flare from true progression in patients with osseous disease at baseline.

A transient rise in PSA levels at therapy initiation has been described in patients receiving taxanes and abiraterone $[15,39]$. In a phase II study in mCRPC treated with abiraterone [39], bone scan flare was observed in a large proportion of patients ( $30 \%$ of the total and $44 \%$ of those who experienced $\mathrm{a} \geq 50 \%$ decline in PSA), suggesting that more investigation is needed to clarify the potentially confounding effect of the bone scan flare phenomena. This flare phenomenon precedes actual response to treatment and can be misinterpreted as therapeutic failure, leading to premature discontinuation of potentially effective agents. While different studies have shown a flare occurrence after abiraterone treatment $[35,40,41]$, no such phenomena have been observed with enzalutamide [42].

The panel reached a strong consensus that a flare is defined as a temporary clinical and/or biochemical worsening of therapy initiation (92\%). They unanimously agreed that flares occur following taxane and abiraterone treatment. There was no consensus on the possible flare effect of enzalutamide.

\section{Topic 5-M0 management}

There is a lack of information in current clinical practice guidelines on which imaging modality should be used for M0 patients. It is crucial to consider the potential impact on survival in an early identification of asymptomatic M1. The ENTHUSE M0 trial found a high frequency of asymptomatic metastasis (32\%) in patients thought to have M0 CRPC, highlighting the urgent need to improve imaging strategies for metastatic disease [43, 44]. Recommendations on when to initiate and repeat imaging in M0 CRPC patients have been published by the RADAR group [28].

The panel voted on the M0 definition criteria proposed by the RADAR group and they strongly agreed that in an M0 CRPC a baseline bone scan is required for a PSA level of $\geq 2 \mathrm{ng} / \mathrm{ml}$ (84\%). The experts reached a strong consensus that a repeat bone scan should be performed if the PSA level rises to $5 \mathrm{ng} / \mathrm{ml}$ after the negative initial bone scan (88\%). They also strongly agreed that for PSA levels of $\geq 5 \mathrm{ng} / \mathrm{ml}$ and a negative bone scan, the test should be repeated every doubling of PSA level thereafter based on PSA testing every 3 months ( $88 \%)$.

The St Gallen 2015 [17] recommendation for men with M0 CRPC was to continue with ADT and add the older endocrine manipulations without proven survival benefit while acknowledging the lack of evidence about the benefits of abiraterone or enzalutamide, while different studies support the use of palliative radiotherapy in this clinical situation.

The panel unanimously agreed that first-line treatment in an M0 CRPC patient with local clinical progression was radiotherapy (if there had been no previous radiotherapy) or salvage surgery. They also unanimously agreed that docetaxel, abiraterone or enzalutamide should not be administered in these cases until evidence from the ongoing randomized clinical trials becomes available.

Even though the results on the benefits of the new antiandrogens were not known when the different phases of the consensus were underway, the results of two phase III studies have confirmed the benefits of enzalutamide (PROSPER) and apalutamide (SPARTAN) in M0 CRPC patients and PSA doubling time $<10$ months $[45,46]$. Both drugs have constistently improved progression free survival compared with placebo, as well as metastasis free survival.

\section{Topic 6-M1 management and sequencing therapy}

Asymptomatic/minimally symptomatic M1 CRPC patient More than $84 \%$ of patients have metastases at CRPC diagnosis. In those without metastases at diagnosis, $33 \%$ of patients with CRPC develop metastases within 2 years of their diagnosis $[6,7,47]$. The new androgen-receptor inhibitors which demonstrates efficacy in the metastatic CRPC setting have changed the paradigm of CRPC treatment [28]. Abiraterone and enzalutamide have been evaluated as firstline agents in asymptomatic patients [48, 49] and are recommended as first-line therapy in the ESMO [50] and SEOM [3] Clinical Practice Guidelines.

The St Gallen consensus $(2015,2017)[17,35]$ agreed that asymptomatic men with mCRPC should receive abiraterone or enzalutamide as first-line treatment, independently of whether they had received ADT alone or ADT plus docetaxel in the castration-naïve setting [16, 34]. Similarly, the EAU-ESTRO-SIOG guidelines [25] proposed different therapies, including abiraterone, enzalutamide, sipuleucel-T and docetaxel, and the URONCOR consensus statement includes sipuleucel-T and abiraterone acetate plus prednisone [21].

Visceral metastases are nowadays more commonly detected [36] and autopsy studies on men who died from prostate cancer suggested a higher prevalence of visceral metastases in up to $66 \%$ of selected cases [51]. Even though this population has a poor prognosis and are frequently 
excluded from other trials, research with new survivalprolonging treatments has changed this paradigm. In the PREVAIL study, enzalutamide treatment showed a consistent benefit in some patients with visceral metastatic disease [52].

The panel unanimously voted that most asymptomatic/ minimally symptomatic M1 CRPC patients should receive abiraterone or enzalutamide as first-line treatment while docetaxel should only be used in some aggressive cases. They unanimously voted not to use docetaxel as a first option in many cases.

In an asymptomatic/minimally symptomatic M1 CRPC patient with visceral metastases, the panel strongly agreed $(80 \%)$ to consider enzalutamide as first-line treatment. They voted unanimously not to consider abiraterone as first-line treatment and reached a strong consensus on not recommending docetaxel as first-line therapy (80\%).

In accordance with the results of COU-32 [53] and PREVAIL [52], the NCCN [30] considers that enzalutamide treatment should be monitored for fatigue, diarrhoea, hot flashes and seizures (reported in $0.9 \%$ of men on enzalutamide). The side effects of abiraterone require monitoring for hypertension, hypokalaemia, peripheral oedema, atrial fibrillation, congestive heart failure, liver injury and fatigue.

The panel strongly agreed that the choice of treatment for these patients would be influenced by the following factors: visceral metastases (96\%), cardiovascular history (72\%), prior seizures (80\%) and steroid contraindications (96\%). Only half of them considered that hypertension would have an influence on their decision.

Finally, there was a strong consensus (88\%) that secondary hormonal manipulations are suitable for patients who are not candidates for chemotherapy, regardless of enzalutamide or abiraterone availability.

Symptomatic M1 CRPC patient The EAU-ESTRO-SIOG guidelines [25] suggest that symptomatic M1 CRPC patients should receive docetaxel as first-line therapy and radium-223 if they have bone/non-visceral metastasis. The second-line choice would include enzalutamide, abiraterone, docetaxel, cabazitaxel or radium-223, depending on previous therapy. The SEOM guidelines [3] also suggest that abiraterone or enzalutamide are an alternative first-line treatment for symptomatic mCRPC patients who are docetaxel-naïve or unfit or unwilling to receive docetaxel.

The panel strong agreed that the first-line therapy for symptomatic M1 CRPC should be docetaxel (84\%) and radium-223 in patients with bone metastases (non-visceral) (92\%), but they did not consider that enzalutamide/abiraterone should be recommended ( $84 \%$ ).

There was a strong consensus that most CRPC patients with symptomatic bone metastasis should receive bone-targeting therapies (bisphosphonates, denosumab) $(88 \%)$ until the onset of the bone progression $(82 \%)$.

Oligometastatic M1 CRPC patient Interest has increased in the potential role of definitive metastasis-directed therapy for men with oligometastatic disease, defined as few (often $\leq 5$ ) metastatic lesions, even in the absence of symptoms [33]. It has been proposed as a distinct clinical entity from metastasis, considered to be an intermediate state of tumour spread with limited metastatic capacity $[32,33]$.

In CRPC patients, the management of men with oligometastatic disease is another area where trial data is lacking, making it an important research question [35].

The panel strongly agreed that local control of oligometastasis decreases symptoms (92\%), delays the start of a new systemic therapy (88\%) and could increase overall survival and/or progression-free survival (84\%).

In the CPRC oligometastatic patient, local ablative therapy in addition to enzalutamide/abiraterone must be considered (92\%) and it was unanimously agreed that a radical prostate treatment should be also considered.

\section{Topic 7-treatment monitoring}

Even though it is generally accepted that regular treatment response monitoring should be undertaken, there are no agreed guidelines on the precise clinical, laboratory and imaging evaluations or on the frequency of scheduling follow-up visits.

According to the EAU-ESTRO-SIOG guidelines, monitoring M1 CPRC treatment should include a physical examination, baseline blood tests, a whole-body CT scan and a bone scan every 6 months.

The NCCN [30] recommend that in M1 patients there must be a physical examination and PSA levels tested every 3-6 months, with a bone scan taken every 6-12 months.

According to the PCWG3 [22], analytical tests should be performed every 3-4 weeks and image tests taken at 8- or 9-week-intervals in case there is a flare occurrence. The URONCOR consensus [21] recommended that patient should be monitored 1 month after initiation therapy and that radiological imaging should be done every 3 months.

Finally, the European consensus of 2014 [14] recommends early imaging at 3 months to detect any resistance to new agents.

There was a strong consensus that a Tc-99 $\mathrm{m}$ bone scan (84\%), a whole-body MRI and/or axial skeleton (92\%), and a Choline PET/TC (84\%) were all suitable to evaluate bone metastasis response to the therapy.

The panel unanimously agreed $(100 \%)$ that in asymptomatic/minimally symptomatic men with M1 CRPC, the choice of first-line therapy influences the frequency of follow-up patient visits, blood tests (84\%) and blood pressure 
monitoring (80\%). Conversely, they strongly agreed that the frequency of imaging tests was not influenced by the firstline therapy choice $(96 \%)$.

The panel also strongly agreed that during the first 3 months of enzalutamide therapy the frequency of patient visits $(80 \%)$, blood tests (84\%) and blood pressure monitoring $(70 \%)$ should be done every month.

During the first 3 months of abiraterone therapy, there was also a strong consensus that the frequency of patient visits (80\%), blood tests (84\%) and additional blood pressure monitoring (70\%) should be undertaken every $1-2$ weeks.

In an asymptomatic/minimally symptomatic M1 CPRC patient, the panel strongly agreed that follow-up tests must be scheduled either every 3-6 months regardless of PSA values $(88 \%)$ or, when PSA levels double (96\%), and they unanimously agreed that follow-up tests should be performed if symptoms related to the metastatic disease appeared (100\%).

In an M1 CPRC symptomatic patient, the panel strongly agreed that follow-up tests must be scheduled either every 3 months regardless of PSA values (84\%) or when PSA levels double $(96 \%)$. They unanimously agreed that follow-up tests should be performed if new symptoms appeared (100\%) but they strongly agreed that 6 months was too infrequent, regardless of PSA values (96\%).

\section{Conclusion}

The present consensus document is intended to be a useful tool, providing radiation oncology specialists with expert guidance on and standards for CRPC patient management in Spain. It provides 116 statements that have been agreed following a modified Delphi method. A strong consensus or unanimity has been reached on 108 out of the 116 (93\%) questions. This is especially important considering that CRPC management is still challenging due to the heterogeneity of the disease, the high number of different therapeutic options available, the lack of head-to-head clinical trials, primary or acquired resistance, and the incidence of metastatic progression. In addition to these guidelines the clinical judgement and experience of the treating physician in clinical practice is also required in the decision-making process for each of the different clinically relevant areas for CRPC patients.

Acknowledgements The authors want to express their gratitude to Astellas Pharma for the financial support provided to carry out this Delphi method consensus and to GOC Networking for their contribution with the methodology used and medical writing support.

Cabeza Rodríguez M.A.; Hospital Universitario 12 de Octubre Madrid, Celada Álvarez F.; Hospital La Fe Valencia, Ferrer Albiach C.; Consorcio Hospitalario Provincial Castellón, Ferrer González F.; Hospital Duran y Reynals Barcelona, Gómez-Iturriaga A.; Hospital de Cruces Vizcaya, Guerrero Grande A.; Hospital Son Espases Palma de
Mallorca, Herruzo Cabrera I.; Hospital Carlos Haya Málaga, Hervás Morón A.; Hospital Ramón y Cajal Madrid, López-Torrecilla J.; Hospital General Universitario- ERESA Valencia, Lozano Martínez A.; Hospital Universitario Virgen de la Arrixaca Murcia, Macías Hernández V.; Hospital Universitario Salamanca, Mira Flores M.; Hospital Arnau de Vilanova LLeida, Morera López R.; Hospital La Paz Madrid, Muñoz García J.; Hospital Infanta Cristina Badajoz, Olivera Vegas J.; Hospital Universitario Fundación Jiménez Díaz Madrid, Palacios Eito A.; Hospital Reina Sofía Córdoba, Rodríguez Melcón I.; Hospital Dr. Negrín Gran Canaria, Salinas Ramos J.; Hospital Santa Lucía de Cartagena Murcia, Samper Ots P.; Hospital Universitario Rey Juan Carlos Madrid, Sancho Pardo G.; Hospital de la Santa Creu i Sant Pau Barcelona.

\section{Compliance with ethical standards}

Conflict of interest The authors declare no conflict of interest in this article.

Research involving human participants and/or animals Not applicable.

Informed consent Not applicable.

Open Access This article is distributed under the terms of the Creative Commons Attribution 4.0 International License (http://creativeco mmons.org/licenses/by/4.0/), which permits unrestricted use, distribution, and reproduction in any medium, provided you give appropriate credit to the original author(s) and the source, provide a link to the Creative Commons license, and indicate if changes were made.

\section{References}

1. Galceran J, Ameijide A, Carulla M, Mateos A, Quiros JR, Rojas D, et al. Cancer incidence in Spain, 2015. Clin Transl Oncol. 2017;19(7):799-825.

2. Rodriguez A, Borras JM, Lopez-Torrecilla J, Algara M, PalaciosEito A, Gomez-Caamano A, et al. Demand for radiotherapy in Spain. Clin Transl Oncol. 2017;19(2):204-10.

3. Cassinello J, Arranz JA, Piulats JM, Sanchez A, Perez-Valderrama B, Mellado B, et al. SEOM clinical guidelines for the treatment of metastatic prostate cancer. Clin Transl Oncol. 2018;20(1):57-68.

4. Chirlaque MD, Salmeron D, Galceran J, Ameijide A, Mateos A, Torrella A, et al. Cancer survival in adult patients in Spain. Results from nine population-based cancer registries. Clin Transl Oncol. 2018;20(2):201-11.

5. Campa J, Mar-Barrutia G, Extramiana J, Arrospide A, Mar J. Advanced prostate cancer survival in Spain according to the Gleason score, age and stage. Actas Urol Esp. 2016;40(8):499-506.

6. Kirby M, Hirst C, Crawford ED. Characterising the castrationresistant prostate cancer population: a systematic review. Int $\mathbf{J}$ Clin Pract. 2011;65(11):1180-92.

7. Inoue T, Segawa T, Kamba T, Yoshimura K, Nakamura E, Nishiyama $\mathrm{H}$, et al. Prevalence of skeletal complications and their impact on survival of hormone refractory prostate cancer patients in Japan. Urology. 2009;73(5):1104-9.

8. Sartor O, de Bono JS. Metastatic prostate cancer. N Engl J Med. 2018;378(7):645-57.

9. Scher HI, Fizazi K, Saad F, Taplin ME, Sternberg CN, Miller K, et al. Increased survival with enzalutamide in prostate cancer after chemotherapy. N Engl J Med. 2012;367(13):1187-97.

10. de Bono JS, Logothetis CJ, Molina A, Fizazi K, North S, Chu L, et al. Abiraterone and increased survival in metastatic prostate cancer. N Engl J Med. 2011;364(21):1995-2005. 
11. Kantoff PW, Higano CS, Shore ND, Berger ER, Small EJ, Penson DF, et al. Sipuleucel-T immunotherapy for castration-resistant prostate cancer. N Engl J Med. 2010;363(5):411-22.

12. Parker C, Nilsson S, Heinrich D, Helle SI, O’Sullivan JM, Fossa $\mathrm{SD}$, et al. Alpha emitter radium-223 and survival in metastatic prostate cancer. N Engl J Med. 2013;369(3):213-23.

13. de Bono JS, Oudard S, Ozguroglu M, Hansen S, Machiels JP, Kocak I, et al. Prednisone plus cabazitaxel or mitoxantrone for metastatic castration-resistant prostate cancer progressing after docetaxel treatment: a randomised open-label trial. Lancet. 2010;376(9747):1147-54.

14. Komura K, Sweeney CJ, Inamoto T, Ibuki N, Azuma H, Kantoff PW. Current treatment strategies for advanced prostate cancer. Int J Urol. 2018;25(3):220-31.

15. Fitzpatrick JM, Bellmunt J, Fizazi K, Heidenreich A, Sternberg $\mathrm{CN}$, Tombal B, et al. Optimal management of metastatic castration-resistant prostate cancer: highlights from a European Expert Consensus Panel. Eur J Cancer. 2014;50(9):1617-27.

16. Alcaraz A, Martinez-Pineiro L, Rodriguez A, Rubio J, Borque A, Burgos J, et al. Consensus on castration-resistant prostate cancer management in Spain. Arch Esp Urol. 2017;70(9):777-91.

17. Gillessen S, Omlin A, Attard G, de Bono JS, Efstathiou E, Fizazi K, et al. Management of patients with advanced prostate cancer: recommendations of the St Gallen Advanced Prostate Cancer Consensus Conference (APCCC) 2015. Ann Oncol. 2015;26(8):1589-604.

18. Armstrong AJ, Garrett-Mayer E, Ou Yang YC, Carducci MA, Tannock I, de Wit R, et al. Prostate-specific antigen and pain surrogacy analysis in metastatic hormone-refractory prostate cancer. J Clin Oncol. 2007;25(25):3965-70.

19. Sternberg C, Armstrong A, Pili R, Ng S, Huddart R, Agarwal $\mathrm{N}$, et al. Randomized, double-blind, placebo-controlled phase III study of tasquinimod in men with metastatic castration-resistant prostate cancer. J Clin Oncol. 2016;34(22):2636-43.

20. Jadad AR, Browman GP. The WHO analgesic ladder for cancer pain management. Stepping up the quality of its evaluation. JAMA. 1995;274(23):1870-3.

21. Lopez Torrecilla J, Hervas A, Zapatero A, Gomez Caamano A, Macias V, Herruzo I, et al. Uroncor consensus statement: management of biochemical recurrence after radical radiotherapy for prostate cancer: From biochemical failure to castration resistance. Rep Pract Oncol Radiother. 2015;20(4):259-72.

22. Scher HI, Morris MJ, Stadler WM, Higano C, Basch E, Fizazi K, et al. Trial design and objectives for castration-resistant prostate cancer: updated recommendations from the prostate cancer clinical trials working group 3. J Clin Oncol. 2016;34(12):1402-18.

23. Ferrer M, Guedea F, Suárez JF, de Paula B, Macías V, Mariño A, et al. Quality of life impact of treatments for localized prostate cancer: cohort study with a 5 year follow-up. Radiother Oncol. 2013;108(2):306-13.

24. Malcolm JB, Fabrizio MD, Barone BB, Given RW, Lance RS, Lynch DF, et al. Quality of life after open or robotic prostatectomy, cryoablation or brachytherapy for localized prostate cancer. J Urol. 2010;183(5):1822-8.

25. Cornford P, Bellmunt J, Bolla M, Briers E, De Santis M, Gross T, EAU-ESTRO-SIOG Guidelines on Prostate Cancer, et al. Part II: treatment of relapsing, metastatic, and castration-resistant prostate cancer. Eur Urol. 2017;71(4):630-42.

26. Smith MR, Cook R, Lee KA, Nelson JB. Disease and host characteristics as predictors of time to first bone metastasis and death in men with progressive castration-resistant nonmetastatic prostate cancer. Cancer. 2011;117(10):2077-85.

27. Smith MR, Kabbinavar F, Saad F, Hussain A, Gittelman MC, Bilhartz DL, et al. Natural history of rising serum prostate-specific antigen in men with castrate nonmetastatic prostate cancer. J Clin Oncol. 2005;23(13):2918-25.
28. Crawford ED, Stone NN, Yu EY, Koo PJ, Freedland SJ, Slovin SF, et al. Challenges and recommendations for early identification of metastatic disease in prostate cancer. Urology. 2014;83(3):664-9.

29. Schwenck J, Rempp H, Reischl G, Kruck S, Stenzl A, Nikolaou K, et al. Comparison of (68)Ga-labelled PSMA-11 and (11)C-choline in the detection of prostate cancer metastases by PET/CT. Eur J Nucl Med Mol Imaging. 2017;44(1):92-101.

30. NCCN clinical practice guidelines in prostate cancer, Version 2.2017, February 21, 2017. https://www.nccn.org/professionals/ physician_gls/pdf/prostate.pdf. Accessed 21 Feb 2017.

31. Singh D, Yi WS, Brasacchio RA, Muhs AG, Smudzin T, Williams JP, et al. Is there a favorable subset of patients with prostate cancer who develop oligometastases? Int J Radiat Oncol Biol Phys. 2004;58(1):3-10.

32. Ost P, Bossi A, Decaestecker K, De Meerleer G, Giannarini G, Karnes RJ, et al. Metastasis-directed therapy of regional and distant recurrences after curative treatment of prostate cancer: a systematic review of the literature. Eur Urol. 2015;67(5):852-63.

33. Weichselbaum RR, Hellman S. Oligometastases revisited. Nat Rev Clin Oncol. 2011;8(6):378-82.

34. Schweizer MT, Zhou XC, Wang H, Yang T, Shaukat F, Partin AW, et al. Metastasis-free survival is associated with overall survival in men with PSA-recurrent prostate cancer treated with deferred androgen deprivation therapy. Ann Oncol. 2013;24(11):2881-6.

35. Gillessen S, Attard G, Beer TM, Beltran H, Bossi A, Bristow $\mathrm{R}$, et al. Management of patients with advanced prostate cancer: the report of the advanced prostate cancer consensus conference APCCC 2017. Eur Urol. 2018;73(2):178-211.

36. Pezaro C, Omlin A, Lorente D, Rodrigues DN, Ferraldeschi R, Bianchini $\mathrm{D}$, et al. Visceral disease in castration-resistant prostate cancer. Eur Urol. 2014;65(2):270-3.

37. Narmala SK, Boulmay BC. PSA flare after initiation of abiraterone acetate. J Commun Support Oncol. 2014;12(5):191-2.

38. Thuret R, Massard C, Gross-Goupil M, Escudier B, Di Palma M, Bossi A, et al. The postchemotherapy PSA surge syndrome. Ann Oncol. 2008;19(7):1308-11.

39. Ryan CJ, Shah S, Efstathiou E, Smith MR, Taplin ME, Bubley GJ, et al. Phase II study of abiraterone acetate in chemotherapynaive metastatic castration-resistant prostate cancer displaying bone flare discordant with serologic response. Clin Cancer Res. 2011;17(14):4854-61.

40. Burgio SL, Conteduca V, Rudnas B, Carrozza F, Campadelli E, Bianchi E, et al. PSA flare with abiraterone in patients with metastatic castration-resistant prostate cancer. Clin Genitourin Cancer. 2015;13(1):39-43.

41. Ueda Y, Matsubara N, Tabata KI, Satoh T, Kamiya N, Suzuki $\mathrm{H}$, et al. Prostate-specific antigen flare phenomenon induced by abiraterone acetate in chemotherapy-naive patients with metastatic castration-resistant prostate cancer. Clin Genitourin Cancer. 2017;15(2):320-5.

42. Armstrong AJ, Saad F, Phung Dmuchowski C, Shore ND, Fizazi $\mathrm{K}$, et al. Clinical outcomes and survival surrogacy studies of prostate-specific antigen declines following enzalutamide in men with metastatic castration-resistant prostate cancer previously treated with docetaxel. Cancer. 2017;123(12):2303-11.

43. Yu EY, Miller K, Nelson J, Gleave M, Fizazi K, Moul JW, et al. Detection of previously unidentified metastatic disease as a leading cause of screening failure in a phase III trial of zibotentan versus placebo in patients with nonmetastatic, castration resistant prostate cancer. J Urol. 2012;188(1):103-9.

44. White R, Khor R, Bressel M, Duchesne G, Williams S, Bowden $\mathrm{P}$, et al. Efficacy of high-dose palliative radiotherapy for localised, castration-resistant prostate cancer. Clin Oncol (R Coll Radiol). 2015;27(1):16-21.

45. Hussain M, Fizazi K, Saad F, Rathenborg P, Shore ND, Demirhan E, et al. PROSPER: A phase 3, randomized, double-blind, placebo 
(PBO)-controlled study of enzalutamide (ENZA) in men with nonmetastatic castration-resistant prostate cancer (M0 CRPC). J Clin Oncol. 2018;36:6_suppl, 3-3.

46. Smith MR, Saad F, Chowdhury S, Oudard S, Hadaschik BA, Graff $\mathrm{JN}$, et al. Apalutamide treatment and metastasis-free survival in prostate cancer. N Engl J Med. 2018;378(15):1408-18.

47. Berruti A, Tucci M, Mosca A, Tarabuzzi R, Gorzegno G, Terrone $\mathrm{C}$, et al. Predictive factors for skeletal complications in hormonerefractory prostate cancer patients with metastatic bone disease. Br J Cancer. 2005;93(6):633-8.

48. Ryan CJ, Molina A, Griffin T. Abiraterone in metastatic prostate cancer. N Engl J Med. 2018;378(15):1408-18.

49. Beer TM, Armstrong AJ, Rathkopf DE, Loriot Y, Sternberg CN, Higano CS, et al. Enzalutamide in metastatic prostate cancer before chemotherapy. N Engl J Med. 2014;371(5):424-33.

50. Parker C, Gillessen S, Heidenreich A, Horwich A. Cancer of the prostate: ESMO Clinical Practice Guidelines for diagnosis, treatment and follow-up. Ann Oncol. 2015;26(Suppl 5):v69-77.
51. Shah RB, Mehra R, Chinnaiyan AM, Shen R, Ghosh D, Zhou M, et al. Androgen-independent prostate cancer is a heterogeneous group of diseases: lessons from a rapid autopsy program. Cancer Res. 2004;64(24):9209-16.

52. Evans CP, Higano CS, Keane T, Andriole G, Saad F, Iversen P, et al. The PREVAIL Study: primary outcomes by site and extent of baseline disease for enzalutamide-treated men with chemotherapy-naïve metastatic castration-resistant prostate cancer. Eur Urol. 2016;70(4):675-83.

53. Ryan CJ, Smith MR, Fizazi K, Saad F, Mulders PF, Sternberg $\mathrm{CN}$, et al. Abiraterone acetate plus prednisone versus placebo plus prednisone in chemotherapy-naive men with metastatic castrationresistant prostate cancer (COU-AA-302): final overall survival analysis of a randomised, double-blind, placebo-controlled phase 3 study. Lancet Oncol. 2015;16(2):152-60. 